\title{
PRODUÇÃO DE SERAPILHEIRA EM DIFERENTES SERES SUCESSIONAIS DA FLORESTA ESTACIONAL SEMIDECIDUAL NO OESTE DO PARANÁ
}

\author{
Anderson W. Pezzatto*, Celina Wisniewski** \\ *Eng. Florestal, M.Sc. - awpezzatto@yahoo.com.br \\ **Eng ${ }^{\mathrm{a}}$. Florestal, Dr ${ }^{\mathrm{a}}$., Depto. de Solos e Engenharia Agrícola, UFPR - cewisni@ufpr.br \\ Recebido para publicação: 05/07/2005 - Aceito para publicação: 28/04/2006
}

\begin{abstract}
Resumo
A vegetação ao longo das margens de um reservatório de hidrelétrica foi classificada em cinco seres sucessionais (fase inicial de sucessão - campo -, capoeirinha, capoeira, capoeirão e floresta secundária). As árvores e arbustos de cada sere foram amostrados em 4 parcelas de $10 \times 20 \mathrm{~m}$, e a produção de serapilheira foi estimada com o uso de 12 coletores por sere $\left(4,0 \mathrm{~m}^{2}\right)$. A quantidade de serapilheira depositada aumentou com o avanço da sucessão $\left(9,5\right.$ a 11,7 Mg.ha $\left.{ }^{-1}\right)$, embora não tenham sido observadas diferenças estatisticamente significativas, com exceção da sere inicial $\left(2,2 \mathrm{Mg} \cdot \mathrm{ha}^{-1}\right)$. A fração folhas representou a maior parte da serapilheira produzida, com a porcentagem diminuindo com o processo sucessional. O máximo de deposição da serapilheira não ocorreu no mesmo período em todas as seres, mas a menor deposição foi observada no verão (dezembro), que correspondeu ao mês de menor precipitação. A serapilheira depositada mostrou correlação positiva significativa com a velocidade média dos ventos, com a velocidade média das rajadas de vento, e correlação negativa com a umidade relativa do ar.

Palavras-chave: Ciclagem de nutrientes; sucessão vegetal; variáveis climáticas.
\end{abstract}

\section{Abstract}

Litterfall in different sucessional stages of Semi-deciduous Seasonal Forest in Western Paraná State. The vegetation along the margins of an hydroeletric power plant reservoir were classified into five sucessional stages (early stage, three intermediary and one advanced stage). Trees and shrubs were identified in experimental units of the $10 \times 20 \mathrm{~m}$, and litter production was estimated through the use of 12 square $\left(4,0 \mathrm{~m}^{2}\right)$ litter collectors. Litterfall increased with succession $\left(9,5\right.$ to $\left.11,7 \mathrm{Mg}^{-h^{-1}}\right)$ although differences were not statistically signifficant, except for the earliest stage $\left(2,2 \mathrm{Mg} \cdot \mathrm{ha}^{-1}\right)$. Leaves represented the higher fraction of litter produced with the percentage decreasing with the successional process. Maximum litterfall did not occurred at the same time of the year for every stage, but minimum litter production was observed in summer (december) corresponding to a lower rainfall period. Litterfall was positivelly correlated with wind speed and gusts of wind and negativelly correlated with humidity of the air.

Keywords: Nutrient cycling; secondary succession; variables climatic.

\section{INTRODUÇ̃̃O}

Originalmente, a Floresta Estacional Semidecidual cobria uma superfície de mais de $80.000 \mathrm{~km}^{2}$, abrangendo parte dos estados do Paraná, São Paulo, Minas Gerais, Mato Grosso, Goiás, Espírito Santo, Rio de Janeiro e Bahia (LEITE; SOHN, 1994). Por desenvolver-se, na maioria das vezes, sobre solos férteis, tanto do ponto de vista químico quanto físico, somando-se a isso o seu grande potencial madeireiro, essa formação florestal foi reduzida a pequenos fragmentos, em geral, muito alterados e em diferentes fases de sucessão (SANQUETTA, 2000).

A rapidez da sucessão natural é variável devido à natureza e à extensão dos distúrbios (BAZZAZ; PICKETT, 1980; GOMEZ-POMPA; VAZQUEZ-YANES, 1981; GUARIGUATA; OSTERTAG, 2001). De acordo com Gomez-Pompa e Vazquez-Yanes (1981), as espécies que surgem no processo de sucessão dependem tanto das características intrínsecas da espécie, do ciclo de crescimento e 
da eficiência fotossintética quanto de fatores externos, dentre eles o fluxo de energia (AERTS; CHAPIN, 2000) e as características do ambiente físico.

A ciclagem dos nutrientes, processo fundamental no funcionamento dos ecossistemas, também é afetada pelo processo de sucessão, tornando-se mais complexa. A produção de serapilheira é considerada como o mais importante fluxo desse ciclo, movimentando nutrientes da vegetação para o solo, onde podem se acumular nos horizontes orgânicos ou ser incorporados ao solo mineral e serem assim reaproveitados pela vegetação (DELITTI, 1984; PRITTCHET, 1986; SANTOS, 1989; MELLO, 1995).

Considerando-se a reduzida quantidade de área com essa formação florestal no estado do Paraná e o pouco que se conhece sobre sua dinâmica e sua recuperação através do processo de sucessão, o objetivo deste trabalho foi estimar a deposição da serapilheira, nas suas diferentes frações, em diferentes seres sucessionais da Floresta Estacional Semidecidual localizadas nas margens e ilhas do reservatório da usina hidrelétrica de Salto Caxias, localizada no oeste do estado do Paraná.

\section{MATERIAL E MÉTODOS}

\section{Descrição da área de estudo}

O presente estudo foi realizado nas margens e ilhas formadas pelo reservatório da usina hidrelétrica de Salto Caxias, no baixo curso do rio Iguaçu, Terceiro Planalto, oeste do estado do Paraná, entre os municípios de Capitão Leônidas Marques e Nova Prata do Iguaçu, situada entre as coordenadas

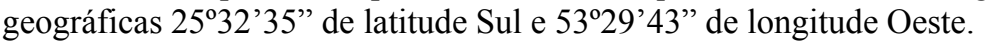

O clima é classificado como Cfa (KÖEPPEN, 1948), definido como subtropical úmido mesotérmico, com chuvas concentradas no verão, sem estação seca bem definida e temperaturas máximas ultrapassando $22{ }^{\circ} \mathrm{C}$. Os verões variam de amenos a quentes, e a ocorrência de geadas é pouco freqüente.

A região faz parte do chamado Altiplano Basáltico Paranaense (LEINZ et al., 1966), onde ocorrem rochas da Formação Serra Geral do Grupo São Bento (basaltos). Em grande parte, são rochas efusivas básicas, ocorrendo em menor grau as ácidas e intermediárias (COPEL, 1993).

A decomposição do basalto originou solos de textura argilosa ou muito argilosa, com características morfológicas diferenciadas em função da posição na paisagem. Em todas as parcelas de estudo, foi identificada a ocorrência de Neossolos, com profundidade média de $20 \mathrm{~cm}$, em declividades que variaram de 14 a 76\%. Os solos das seres campo e capoeirinha foram classificados como Neossolos Litólicos Eutróficos típicos, e das seres capoeira, capoeirão e floresta secundária, Neossolos Regolíticos Eutróficos lépticos. São solos pouco profundos, pouco evoluídos e sem a presença de um horizonte B diagnóstico que diferem basicamente pela presença, nos Neossolos Regolíticos observados, de fragmentos de rocha semi-intemperizada e fragmentos formados por restos da estrutura orientada do basalto dentro de um metro de profundidade.

A vegetação da área de estudo faz parte de um ecótono, área de tensão ecológica, caracterizada pela penetração de espécies típicas da Floresta Estacional Semidecidual na Floresta Ombrófila Mista, em função de seu maior poder de competição e da altitude (IBGE, 1990; VELOSO et al., 1991).

\section{Coleta e análise dos dados}

Com a utilização de imagem do satélite LANDSAT-5 TM, de setembro de 1996, órbita/ponto 223/78 quadrante B, fotografias aéreas em preto e branco, na escala de 1:20.000, ambas cedidas pela Companhia de Energia Elétrica do Paraná (COPEL), e incursões ao campo, a vegetação foi separada em fases sucessionais distintas. Através da fotointerpretação das fotografias aéreas, foi possível classificar a vegetação, de maneira preliminar, em função do grau de alteração antrópica, refletidas nas tonalidades do cinza. A imagem de satélite foi submetida aos processos de realce do contraste dos níveis de cinza e, depois, a uma classificação supervisionada. A vegetação foi posteriormente checada em campo e, considerando-se as características das espécies observadas, classificada em: fase inicial de sucessão (pastagem abandonada), denominada de campo; capoeirinha; capoeira; capoeirão e floresta secundária. Foram alocadas 4 parcelas experimentais justapostas, de 10 × $25 \mathrm{~m}$ por sere sucessional, formando um bloco com 4 repetições.

As parcelas foram divididas em subunidades amostrais (compartimentos), com dimensões de $5 \mathrm{x}$ $10 \mathrm{~m}$ e ainda de $2 \times 5 \mathrm{~m}$, destinadas ao levantamento de indivíduos de diferentes classes dimensionais. Nas parcelas de $10 \times 25 \mathrm{~m}$ (compartimento A), foram mensurados os indivíduos com diâmetro à altura do 
peito (DAP) igual ou superior a $10 \mathrm{~cm}$. Nas subunidades de 5 x $10 \mathrm{~m}$ (compartimento B), foram mensurados os indivíduos com DAP igual ou maior a 3,8 até $10 \mathrm{~cm}$, e nas sub-unidades de 2 x $5 \mathrm{~m}$ (compartimento C) foram estudados os indivíduos que compõem a regeneração natural, com DAP inferior a $3,8 \mathrm{~cm}$ e altura superior a $3 \mathrm{~m}$. Em cada parcela e compartimento, foi coletado material vegetal para identificação e elaboração de herbário segundo Fidalgo e Bononi (1984). A identificação das espécies foi realizada através de bibliografia especializada, comparação com material de herbário e consulta a especialistas. A análise fitossociológica foi realizada com o uso do programa Florexcel (ARCE, 2003).
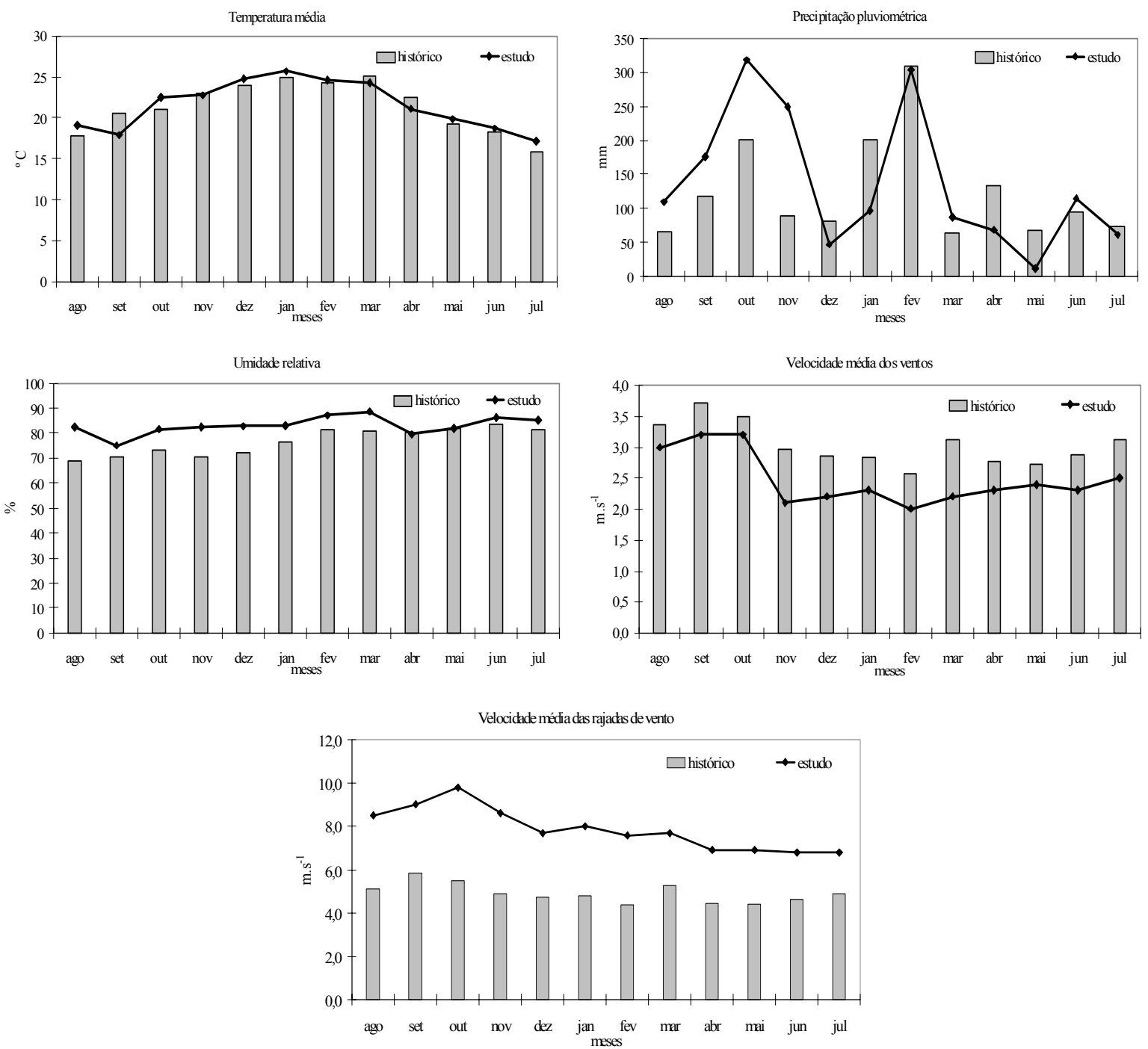

Figura 1. Dados meteorológicos mensais da área de estudo (agosto de 2002 a julho de 2003) e seus respectivos valores históricos.

Figure 1. Monthly meteorological data of the study area (august, 2002 to july, 2003) and its respective historical values.

A amostragem mensal da serapilheira foi feita instalando-se 12 coletores por sere sucessional (3 por parcela), número este definido através do procedimento de Stein (1945), citado por Steel e Torrie (1960). Cada coletor foi confeccionado com tela plástica de malha 2 x $2 \mathrm{~mm}$ e armação de PVC $40 \mathrm{~mm}$ $(0,58 \times 0,58 \mathrm{~m})$, com uma área de $0,336 \mathrm{~m}^{2}\left(1,008 \mathrm{~m}^{2}\right.$ por parcela). Os coletores foram implantados na 
área no dia 19 de julho de 2002. A primeira coleta foi realizada no dia 20 de agosto de 2002, sendo então realizadas a cada mês até o dia 20 de julho de 2003, completando 12 coletas.

O material depositado foi recolhido em sacos de papel e secado ao ar. Em seguida, foi separado nas frações folhas, galhos (até $2 \mathrm{~cm}$ de diâmetro) e "outros" (flores, frutos, cascas e material não identificável). Posteriormente, esse material foi secado em estufa à temperatura de $60 \pm 5{ }^{\circ} \mathrm{C}$, até peso constante, e em seguida pesado, estimando-se a deposição por hectare.

A análise estatística foi realizada com o emprego do programa Statgraphics Plus 4.1, seguindo um delineamento em blocos ao acaso. Procedeu-se a ANOVA, com posterior comparação das médias através do teste de Tukey, ao nível de $10 \%$ de probabilidade, adotada em virtude da grande variação observada na quantidade de material depositado nas diferentes seres sucessionais. Foram também calculados os coeficientes de correlação entre a serapilheira depositada e as variáveis meteorológicas: temperatura média, precipitação pluviométrica, umidade relativa do ar, velocidade média dos ventos e velocidade média das rajadas de vento referentes à área de estudo, obtidas na estação meteorológica localizada junto à usina hidrelétrica e disponibilizadas pelo Sistema Meteorológico do Paraná SIMEPAR (Figura 1).

\section{RESULTADOS E DISCUSSÃO}

Foram mensurados 494 indivíduos, dos quais 38 eram indivíduos mortos. Observaram-se 76 espécies arbóreo-arbustivas, sendo 3 não identificadas, pertencentes a 38 famílias botânicas, das quais 3 não foram identificadas.

Na sere campo, foram amostrados 41 indivíduos (3 mortos), distribuídos em 14 espécies arbóreoarbustivas pertencentes a 13 famílias. Na capoeirinha, foram mensurados 106 indivíduos (11 mortos), compreendidos em 28 espécies e distribuídos em 19 famílias. Na capoeira, foram amostrados 107 indivíduos (8 mortos), pertencentes a 31 espécies distribuídas em 20 famílias. No capoeirão, foram mensurados 119 indivíduos (7 mortos), distribuídos em 41 espécies pertencentes a 25 famílias. Na floresta secundária, foram amostrados 121 indivíduos (9 mortos), distribuídos em 36 espécies pertencentes a 23 famílias.

Pode-se observar que ocorre um acréscimo do número de indivíduos mensurados e da riqueza de espécies com o avanço da sucessão (campo - capoeirão), até mostrar uma estabilização em riqueza de espécies (floresta secundária). Segundo Ribas et al. (2003), isso é uma tendência natural no processo sucessional, que vai se estabilizando nas seres mais avançadas.

As principais espécies em índice de valor de importância observadas nas seres sucessionais foram: campo: Trema micrantha L., Blume, Lonchocarpus guilleminianus (Tul.) Malme e Psidium guajava L.; capoeirinha: Cecropia pachystachya Trécul., Aloysia virgata (Ruiz e Pav.) Juss. e Piper sp.; capoeira: Nectandra megapotamica (Spreng.) Mez, Casearia sylvestris Sw. e Sebastiania brasiliensis Spreng.; capoeirão: Alchornea triplinervia (Spreng.) Müll. Arg., Casearia sylvestris Sw. e Actinostemon concolor (Spreng.) Müll. Arg.; floresta secundária: Euterpe edulis Mart., Sorocea bomplandii (Baill.) W.C. Burger, Lanj. e Wess. Boer e Actinostemon concolor (Spreng.) Müll. Arg.

Embora possam ser encontradas espécies características de ambientes mais bem conservados, como Euterpe edulis, em geral as espécies pioneiras, como Trema micrantha, Cecropia pachystachya, Aloysia virgata e Casearia sylvestris são as mais representativas, resultado da alteração do ambiente original, iniciada com a exploração madeireira no passado e seguida da utilização dessas áreas principalmente para pecuária.

Observa-se que, mesmo em ambiente ciliar, a baixa disponibilidade de água, característica desse tipo de solo, dificulta o aparecimento de espécies relacionadas a locais úmidos, promovendo assim o desenvolvimento de espécies adaptadas a ambientes bem drenados, como Nectandra megapotamica, Casearia sylvestris e Actinostemon concolor (DIAS et al., 1998; SOUZA, et al., 2003).

A tabela 1 mostra a produção média anual da serapilheira, em $\mathrm{kg} \cdot \mathrm{ha}^{-1}$, em que se observa que a quantidade total de serapilheira depositada nas diferentes seres aumenta conforme o avanço da sucessão vegetal, embora as quantidades totais depositadas de serapilheira não mostrem diferenças estatisticamente significativas da sere capoeirinha até a floresta secundária. 
Tabela 1. Quantidade (kg.ha $\left.{ }^{-1}\right)$ de serapilheira depositada nas diferentes seres sucessionais da Floresta Estacional Semidecidual, Paraná.

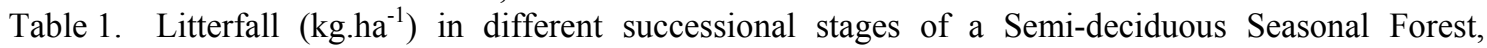
Paraná.

\begin{tabular}{|c|c|c|c|c|c|c|c|c|c|c|c|c|c|c|c|}
\hline \multirow{3}{*}{$\begin{array}{l}\text { Fração } \\
\text { Folhas }\end{array}$} & \multicolumn{3}{|c|}{ Campo } & \multicolumn{3}{|c|}{ Capoeirinha } & \multicolumn{3}{|c|}{ Capoeira } & \multicolumn{3}{|c|}{ Capoeirão } & \multicolumn{3}{|c|}{ F. secundária } \\
\hline & \multicolumn{2}{|l|}{ kg.ha ${ }^{-1}$} & \multirow{2}{*}{$\begin{array}{c}\% \\
73,7\end{array}$} & \multicolumn{2}{|l|}{ kg.ha ${ }^{-1}$} & \multirow{2}{*}{$\frac{\%}{64,0}$} & \multicolumn{2}{|l|}{ kg.ha ${ }^{-1}$} & \multirow{2}{*}{$\begin{array}{c}\% \\
56,1\end{array}$} & \multicolumn{2}{|c|}{ kg.ha ${ }^{-1}$} & \multirow{2}{*}{$\begin{array}{c}\% \\
61,7\end{array}$} & \multicolumn{2}{|l|}{ kg.ha ${ }^{-1}$} & \multirow{2}{*}{$\begin{array}{c}\mathbf{\%} \\
52,4\end{array}$} \\
\hline & $1.644,58$ & B & & $6.139,71$ & A & & $5.647,96$ & A & & $6.396,82$ & A & & $6.133,77$ & A & \\
\hline Galhos & 400,61 & $\mathrm{C}$ & 17,9 & $2.034,73$ & B & 21,2 & $3.336,57$ & A & 33,1 & $2.890,11$ & $\mathrm{AB}$ & 27,9 & $3.457,61$ & A & 29,6 \\
\hline Outros & 186,51 & $\mathrm{C}$ & 8,4 & $1.415,53$ & $\mathrm{~B}$ & 14,8 & $1.085,65$ & B & 10,8 & $1.085,45$ & B & 10,5 & $2.108,70$ & A & 18,0 \\
\hline Total & $2.231,71$ & B & 100 & $9.589,97$ & A & 100 & $10.070,18$ & A & 100 & $10.372,39$ & A & 100 & $11.700,08$ & A & 100 \\
\hline
\end{tabular}

Médias seguidas da mesma letra, na horizontal, não diferem estatisticamente entre si pelo teste de Tukey ao nível de $10 \%$ de probabilidade.

Exceto no campo, as quantidades produzidas nas demais seres foram superiores às encontradas por Santos (1989), que observou $9.014 \mathrm{~kg} \cdot \mathrm{ha}^{-1}$, e inferiores às encontradas por Trevisan (1998), que estimou $12.788 \mathrm{~kg} \cdot \mathrm{ha}^{-1}$ para a mesma formação florestal sobre solos de alta fertilidade e influência do mesmo tipo de clima no norte do Paraná. De maneira geral, as quantidades observadas de serapilheira depositada foram maiores do que as encontradas em Floresta Estacional Semidecidual, no interior de São Paulo, por Meguro et al. (1979), 9.400 kg.ha- ${ }^{-1}$; Pagano (1989), 8.643 kg.ha ${ }^{-1}$; Cesar (1993), 8.800 kg.ha ${ }^{-1}$; Schlitter et al. (1993), 7.569 kg.ha ${ }^{-1}$; Durigan et al. (1996), 11.126 kg.ha $^{-1}$; Diniz e Pagano (1997), 11.591 kg.ha ${ }^{-1}$, e Souza et al. (2003), $7.466 \mathrm{~kg} \cdot \mathrm{ha}^{-1}$,. Também foram maiores quando comparadas com as produções observadas em Floresta Ombrófila Mista, por Britez et al. (1992), 6.527 kg.ha-1, e Figueiredo et al. (2003), 7.993 kg.ha ${ }^{-1}$, no Paraná, e por Floss et al. (1999), 8.348 kg.ha ${ }^{-1}$, em Santa Catarina.

As maiores produções de serapilheira observadas no presente estudo podem estar relacionadas ao fato de que a vegetação das áreas em recuperação apresenta uma dinâmica mais intensa, comparando-se com áreas relativamente conservadas, como sugerido por Schlitter et al. (1993), após constatar que áreas mais perturbadas produziram quantidades maiores de serapilheira.

A porcentagem correspondente à fração folhas tendeu a diminuir, ao passo que a das outras frações aumentou com o avanço da sucessão, assim como também foi verificado em diferentes seres sucessionais por Cunha (1997), em Floresta Estacional Decidual do Rio Grande do Sul, e por Toledo et al. (2002), em Floresta Atlântica, no estado do Rio de Janeiro. Segundo Carpanezzi (1997), existe um padrão de produção de serapilheira relacionado com a idade dos indivíduos, em que a taxa de deposição e o valor máximo de deposição são próprios para cada caso, e, posteriormente, o valor da deposição de folhas estabiliza-se ou diminui lentamente nas espécies das seres mais avançadas da sucessão, ou diminui rapidamente para as espécies das seres iniciais. As porcentagens observadas de cada fração estão dentro dos valores relatados por vários autores, em estudos realizados na Floresta Estacional Semidecidual e Floresta Ombrófila Mista: de 57\% a 77\% para a fração folhas, de $16 \%$ a $33 \%$ para os galhos e de $1 \%$ a 16\% para outros (MEGURO et al., 1979; PAGANO, 1989; BRITEZ et al., 1992; CESAR, 1993; SCHLITTLER et al., 1993; DIAS; OLIVEIRA-FILHO, 1997; DINIZ; PAGANO, 1997; FIGUEIREDO et al., 2003).

A sere capoeirinha apresentou uma produção maior da fração outros comparada com a capoeira e o capoeirão. Isso é devido à grande densidade da espécie Aloysia virgata, responsável por uma intensa deposição de flores e frutos, principalmente nos meses de janeiro e fevereiro. Quanto à floresta secundária, grande parte do material correspondente à fração "outros" é resultado da deposição de frutos de Euterpe edulis, espécie com maior número de indivíduos dessa sere.

As deposições mensais da serapilheira e suas frações são mostradas na figura 2. Os máximos de deposição não coincidiram em todas as seres (campo: agosto e novembro; capoeirinha: janeiro e fevereiro; capoeira: agosto e novembro; capoeirão: setembro e janeiro; e floresta secundária: agosto e setembro), mas verificou-se que a menor deposição em todas as seres ocorreu em dezembro, mês que apresentou a menor precipitação pluviométrica. 

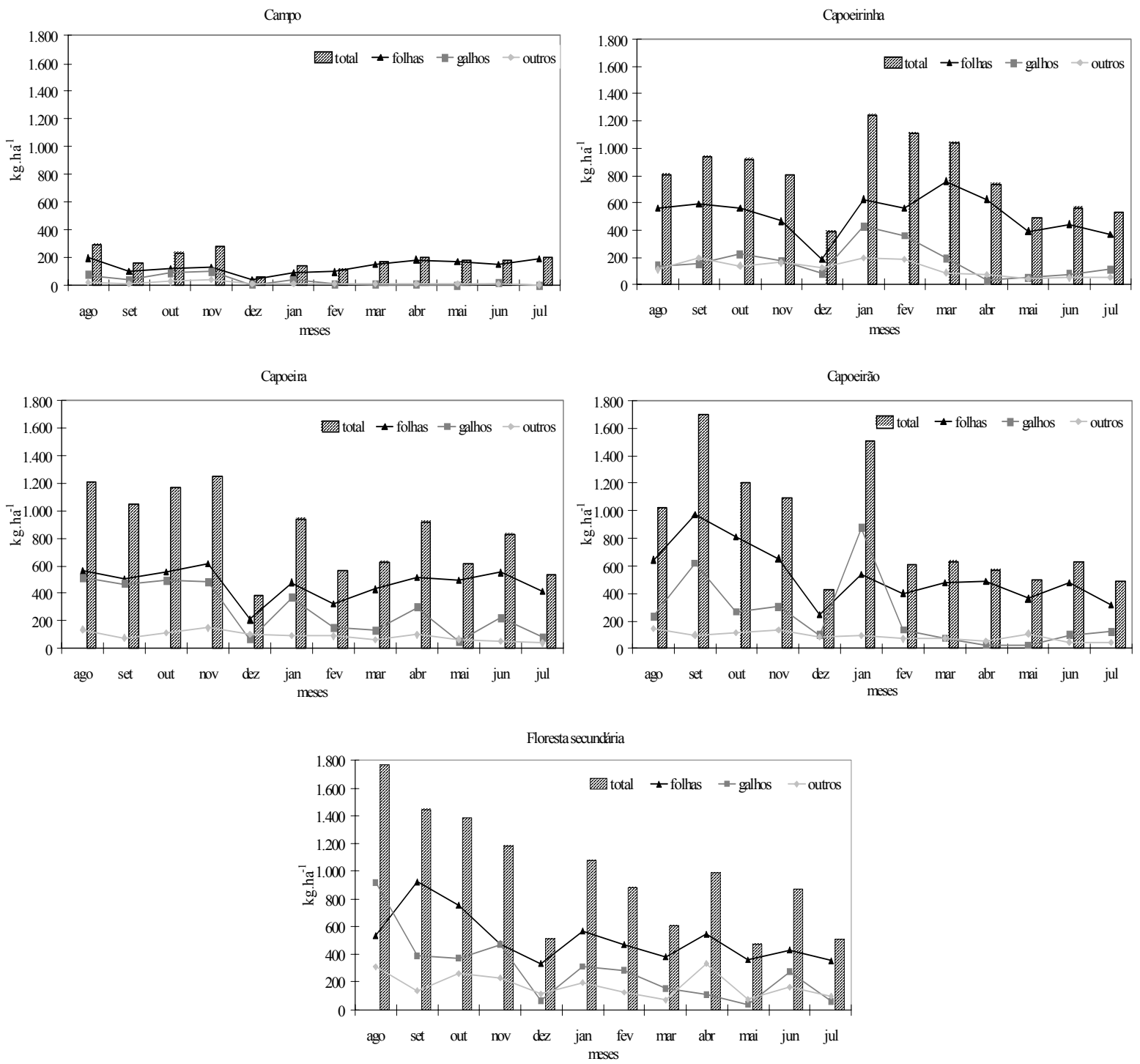

Figura 2. Deposição de serapilheira e suas frações durante o período do estudo (de agosto de 2002 a julho de 2003) em cada sere sucessional da Floresta Estacional Semidecidual.

Figure 2. Litterfall components (august, 2002 to july, 2003) in each successional stage of a Semi-deciduous Seasonal Forest.

As seres capoeira, capoeirão e floresta secundária concentraram as maiores deposições de material nos meses de agosto a novembro. Já a capoeirinha, e em menor grau o campo, não mostram o mesmo padrão. Isso pode ser atribuído às características das espécies que dominam as seres iniciais (Aloysia virgata, Trema micrantha, Piper sp.), que apresentam uma perda de folhas mais intensa e, de certa forma, uma deposição mais uniforme ao longo do ano, característica de espécies consideradas pioneiras (BRAY; GORHAM, 1964; GOMEZ-POMPA; VAZQUEZ-YANES, 1981; GUARIGUATA; OSTERGA, 2001). Segundo Poggiani e Schumacher (2000), essa uniformidade na deposição de serapilheira exerce um papel fundamental na proteção do solo, proporcionando uma cobertura mais contínua durante todo o ano.

As correlações entre as deposições de serapilheira e as variáveis meteorológicas mostraram-se de fracas a moderadas $(r \leq 0,500)$, podendo-se destacar apenas as deposições da capoeira, do capoeirão e da 
floresta secundária, que foram influenciadas positivamente pela velocidade média dos ventos e pela velocidade média das rajadas de vento, e, no caso do capoeirão, ainda, negativamente, pela umidade relativa do ar (Tabela 2).

Tabela 2. Coeficiente de correlação (r) e nível de significância (p) entre a serapilheira depositada e as variáveis meteorológicas.

Table 2. Correlation coefficient (r) and significance level (p) for litterfall and meteorological data.

\begin{tabular}{lcccccccccc}
\hline \multirow{2}{*}{ Sere } & \multicolumn{2}{c}{ Temp. média } & \multicolumn{2}{c}{ Precipitação } & \multicolumn{2}{c}{ U. R. } & \multicolumn{2}{c}{ Vel. média mensal } & \multicolumn{2}{c}{ Vel. média raj. } \\
& $\mathbf{r}$ & $\mathbf{p}$ & $\mathbf{r}$ & $\mathbf{p}$ & $\mathbf{r}$ & $\mathbf{p}$ & $\mathbf{r}$ & $\mathbf{p}$ & $\mathbf{r}$ & $\mathbf{p}$ \\
\hline Campo & $-0,184$ & 0,210 & 0,090 & 0,542 & $-0,067$ & 0,653 & 0,172 & 0,242 & 0,136 & 0,358 \\
Capoeirinha & 0,353 & 0,014 & 0,391 & 0,006 & 0,041 & 0,780 & 0,052 & 0,727 & 0,348 & 0,016 \\
Capoeira & $-0,138$ & 0,350 & 0,374 & 0,009 & $-0,387$ & 0,007 & 0,434 & 0,002 & 0,544 & 0,000 \\
Capoeirão & 0,003 & 0,982 & 0,370 & 0,010 & $-0,520$ & 0,000 & 0,525 & 0,000 & 0,680 & 0,000 \\
F. secundária & $-0,125$ & 0,397 & 0,380 & 0,008 & $-0,374$ & 0,009 & 0,504 & 0,000 & 0,556 & 0,000 \\
\hline
\end{tabular}

Temperatura média mensal (Temp. média), precipitação pluviométrica mensal (Precipitação), umidade relativa média mensal (U. R.), velocidade média mensal dos ventos (Vel. média mensal) e velocidade média mensal das rajadas de vento (Vel. média raj.)

Tradicionalmente, na região, os meses de agosto, setembro e outubro apresentam ventos mais fortes e constantes, porém em relação à precipitação pluviométrica, o período de estudo foi atípico, podendo estar as maiores deposições de serapilheira, em especial da capoeira, capoeirão e floresta secundária, relacionadas com fatores evolutivos das espécies destas seres, e não com o padrão meteorológico apresentado durante o período do estudo (POGGIANI; SCHUMACHER, 2000).

Alguns picos de deposição de serapilheira ocorreram no mês seguinte à baixa precipitação, mostrando o mesmo padrão observado por Santos (1989), em seu estudo realizado em Floresta Estacional Semidecidual, sob clima Cfa, em que a maior queda de folhas ocorreu logo após os meses mais secos (julho, agosto e setembro), embora o autor não tenha detectado correlação estatística entre fatores climáticos e queda de serapilheira. Britez et al. (1992), estudando a Floresta Ombrófila Mista, também verificaram que a maior deposição se deu na primavera, quando do aumento da precipitação e da temperatura.

Outros autores, em estudos na Floresta Estacional Semidecidual, encontraram maiores produções nos meses mais secos do ano, com ênfase no final da estação seca, início da estação chuvosa (SCHLITTLER et al., 1993; CESAR, 1993; DIAS; OLIVEIRA, 1997; DINIZ; PAGANO, 1997; TEIXEIRA et al., 2001; SOUZA et al., 2003). Poggiani e Monteiro Jr. (1990) também constataram que os meses com menor pluviosidade coincidiram com os meses de maior produção de serapilheira, mas também encontraram correlação positiva com menores médias de temperatura, assim como König et al. (2002), em floresta secundária na formação Estacional Decidual. Já Cunha (1997), estudando três seres sucessionais na Floresta Estacional Decidual, observou uma relação entre maior deposição de serapilheira e maior pluviosidade. Diferente de Brun (2002), que, estudando as seres capoeirão, floresta secundária e a floresta primária, verificou correlação significativa entre deposição de serapilheira e velocidade média do vento.

Vários autores, por outro lado, observaram uma baixa correlação entre a produção de serapilheira em Floresta Estacional Semidecidual e as variáveis meteorológicas (MEGURO et al., 1979; PAGANO, 1989; CESAR, 1993; OLIVEIRA; LACERDA, 1993; TREVISAN, 1998). Alguns parâmetros essenciais à manutenção da comunidade vegetacional independem das variações climáticas, uma vez que são resultantes do processo evolutivo dos ecossistemas, da composição das espécies, do comportamento fenológico e da sere sucessional (SANTOS et al., 1984; PINTO; NUNES, 2003).

\section{CONCLUSÕES}

A quantidade de serapilheira depositada mostrou uma tendência de aumento com o processo de sucessão, embora não tenham sido observadas diferenças estatisticamente significativas, exceto quando a sere campo foi comparada com as demais. 
A fração folhas representou a maior porcentagem da serapilheira depositada em todas as seres, seguida pela fração galhos e pela fração outros.

Uma variação estacional expressiva na produção de serapilheira só foi observada nas seres mais desenvolvidas, que apresentaram máximos no final do inverno e início da primavera. As menores deposições em todas as seres coincidiram com o início do verão, período em que se observou a menor precipitação pluviométrica.

Nas seres capoeira, capoeirão e floresta secundária, a deposição de serapilheira foi correlacionada positivamente com a velocidade média dos ventos e das rajadas de vento. Na fase capoeirão, a deposição correlacionou-se negativamente com a umidade relativa do ar.

\section{AGRADECIMENTOS}

Os autores agradecem ao Conselho Nacional de Desenvolvimento Científico e Tecnológico (CNPq), à Fundação de Pesquisas Florestais do Paraná (FUPEF) e aos Professores Carlos Roberto Sanquetta e Paulo de Tarso de Lara Pires, pelo apoio e colaboração para a realização deste trabalho.

\section{REFERENNCIAS}

AERTS, R.; CHAPIN III, F. S. The mineral nutrition of wild plants revisited: re-evaluation of processes and patterns. In.: FILLER, A. H.; RAFFAELLI, D. G. (Eds.). Advances in ecological research. San Diego: Academic, 2000. v. 30, p.1-67.

ARCE, J. E. Florexcel 1.0.13 (beta). Curitiba : [s.n.], 2003.

BAZZAZ, F. A.; PICKETT, S. T. A. Physiological ecology of tropical succession: A comparative review. Annual Review Of Ecology And Systematics, Palo Alto, n. 11, p. 287-310, 1980.

BRAY, J. R.; GORHAM, E. Litter production in forests of the world In: GRAGG, J. B. (Eds.). Advances in ecological research. Londres : Academic, 1964. v. 2, p. 101-157.

BRITEZ, R. M. de; REISSMANN, C. B.; SILVA, S. M.; SANTOS FILHO, A. dos. Deposição estacional de serapilheira e macronutrientes em uma floresta de araucária. São Mateus do Sul, PR. In: CONGRESSO NACIONAL SOBRE ESSÊNCIAS NATIVAS, 2., 1992, São Paulo. Anais... São Paulo : Instituto Florestal, 1992. p. 766-772.

BRUN, E. J. Dinâmica da deposição de serapilheira em três fases sucessionais de uma floresta estacional decidual em Santa Maria, RS. Santa Maria : UFSM, 2002.

CARPANEZZI, A. A. Deposição de material orgânico e nutrientes em uma floresta natural e em uma plantação de eucalipto no interior do estado de São Paulo, Piracicaba. Dissertação (Mestrado em Engenharia Florestal) - Escola Superior de Agricultura "Luiz de Queiroz", Universidade de São Paulo, Piracicaba, 1980.

CESAR, O. Produção de serapilheira na mata mesófila semidecídua da Fazenda Barreiro Rico, município de Anhembi, SP. Revista Brassileira de Biologia, São Paulo, v. 53, n. 4, p. 671-681, 1993.

COPEL. Estudo de Impacto Ambiental - Meio Físico. Curitiba, 1993. v.2

CUNHA, G. C. da. Aspectos da ciclagem de nutrientes em diferentes fases sucessionais de uma floresta estacional do Rio Grande do Sul. Piracicaba. Dissertação (Mestrado em Ciências Florestais) Escola Superior de Agricultura "Luiz de Queiroz”, Universidade de São Paulo, Piracicaba, 1997.

DELITTI, W. B. C. 1984. Estudos de ciclagem de nutrientes: instrumentos para a análise funcional de ecossistemas terrestres. Oecologia Brasiliensis, Rio de Janeiro, v. 1, p. 469-486.

DIAS, H. C. T., OLIVEIRA-FILHO, A. T. de. Variação temporal e espacial da produção de serapilheira em uma área de floresta estacional semidecidual montana em Lavras - MG. Revista Árvore, Viçosa, M.G., v. 21, n. 1, p. 11-26, 1997. 
DIAS. M. C.; VIEIRA, A. O. S.; NAKAJIMA, J. N.; PIMENTA, J. A.; LOBO, P. C. Composição florística e fitossociologia do componente arbóreo das florestas ciliares do rio Iapó, na bacia do rio Tibagi, Tibagi, PR. Revista Brasileira de Botânica, São Paulo, v. 21, n. 2, p. 93-99, 1998.

DINIZ, S., PAGANO, S. N. Dinâmica de folhedo em floresta mesófila semidecídua no município de Araras, SP. I - Produção, deposição e acúmulo. Revista do Instituto Florestal, São Paulo, v. 9, n. 1, p. 27-36, 1997.

DURIGAN, G., LEITÃO-FILHO, H. F., PAGANO, S. N. Produção de folhedo em matas ciliares na Região Oeste do Estado de São Paulo. São Paulo. Revista do Instituto Florestal, São Paulo, v. 8, n. 2, p. 187-199, 1996.

FIDALGO, O.; BONONI, V. L. R. Técnicas de coleta, preservação e herborização de material botânico. São Paulo : Instituto de Botânica, 1984. v.4.

FIGUEIREDO FILHO, A., MORAES, G. F., SCHAAF, L. B., FIGUEIREDO, D. J. de. Avaliação estacional da deposição de serapilheira em uma floresta ombrófila mista localizada no Sul do Estado do Paraná. Ciência Florestal, Santa Maria, v. 13, n. 1, p. 11-18, 2003.

Floss, P. A.; CAlGATO, P. A.; BOHNER, J. A. M. Produção e decomposição de serapilheira na floresta ombrófila mista da reserva florestal da EPAGRI/EMBRAPA de Caçador, SC. Agropecuária Catarinense, Florianópolis., v. 12, n. 2, p. 19-22, 1999.

GOMEZ-POMPA, A.; VAZQUEZ-YANES, C. Successional studies of a rain Forest in México. In.: FOREST succession: concept and application. [S.1. : s.n.], 1981. p. 246-267,

GUARIGUATA, M. R.; OSTERTAG, R. Neotropical secondary Forest successiona: changes in structural and functional characteristics. Forest Ecology and Management, Amsterdan, v. 148, p. 185-206, 2001.

IBGE. Geografia do Brasil: Região Sul. Rio de Janeiro, 1990. v.2.

KÖNIG, F. G.; SCHUMACHER, M. V.; BRUN, J. E.; SELING, I. Avaliação da sazonalidade da produção de serapilheira numa floresta estacional decidual no município de Santa Maria-RS. Revista Árvore, Viçosa, M.G., v. 26, n. 4, p. 429-435. 2002.

KÖEPPEN, W. Climatologia, com um estúdio de los climas de la tierra. Madri : [s.n.], 1948.

LEINZ, V. BARTORELLI, A.; SADOWSKI, G. R.; ISOTTA, C. A. L. Sobre o comportamento espacial do Trapp basáltico da bacia do Paraná. Boletim SBG, São Paulo, v. 15, n. 4 p. 79-91, 1966.

LEITE, P. F.; SOHN, S. Vegetação: as regiões fitoecológicas, sua natureza e seus recursos econômicos. Estudo fitogeográfico. In: Folha SG-22 Curitiba, PR. parte da folha SG-21. Asuncion e folha SG-23 Iguape. [Rio de Janeiro] : IBGE, 1994. No prelo.

MEGURO, M.; VINUZA, G. N.; DELITTI, W. B. C. Ciclagem de nutrientes na mata mesófila secundária - São Paulo. I - Produção e conteúdo de nutrientes minerais no folhedo. Boletim de Botânica, São Paulo., n.7, p. 11-31, 1979.

MELLO, R. S. P. Produção de serapilheira e aspectos da ciclagem de nutrientes em dois tipos florestais adjacentes no Rio Grande do Sul. 136 f. Dissertação (Mestrado em Ciências Biológicas) Universidade Federal do Rio Grande do Sul, Porto Alegre, 1995.

OLIVEIRA, R. R.; LACERDA, L. D. Produção e composição química da serapilheira na floresta da Tijuca (RJ). Revista Brasileira de Botânica, São Paulo, v. 16, n. 1, p. 93-99, 1993.

PAGANO, S. N. Produção de folhedo em mata mesófila semidecídua, no município de Rio Claro. Revista Brasileira de Biologia, Rio de Janeiro, v. 49, n. 3, p. 633-639, 1989.

PINTO, M. T. C., NUNES, F. P. Produção de serapilheira em mata nativa e reflorestamento ciliares do rio São Francisco, MG. In: CONGRESSO DE ECOLOGIA DO BRASIL, 2003, Fortaleza. [Anais...]. [S.1. : s.n.], 2003. p. 560-562. 
POGGIANI, F.; MONTEIRO JUNIOR, E. dos S. Deposição de folhedo e retorno de nutrientes ao solo numa floresta estacional semidecídua, em Piracicaba (Estado de São Paulo) In: CONGRESSO FLORESTAL BRASILEIRO, 1999, Campos do Jordão, SP. [Anais...]. \{S.1.: s.n.], 1990. p. 596-602.

POGGIANI, F. SCHUMACHER, M. V. Ciclagem de nutrientes em florestas nativas. In. GONÇALVES, J. L. M.; BENEDETTI, V (Eds.). Nutrição e fertilização florestal. Piracicaba : IPEF/Escola Superior de Agricultura Luiz de Queiroz, 2000. 247p.

PRITTCHET, W. L. Suelos forestales: propiedadas, conservacion y mejoramiento. México : Limusa. $1986.634 \mathrm{p}$.

RIBAS, R. F.; MEIRA-NETO, J. A. A.; SILVA, A. F. da; SOUZA, A. L. de. Composição florística de dois trechos em diferentes etapas serais de uma floresta estacional semidecíduas em Viçosa, Minas Gerais. Viçosa. Revista Árvore, Viçosa, M.G., v. 27, n. 6, p. 821-830, 2003.

SANQUETTA, C. R. Avaliação biométrica da dinâmica da regeneração natural em áreas degradadas. In: SIMPÓSIO NACIONAL DE RECUPERAÇÃO DE ÁREAS DEGRADADAS, 2000, Blumenau, SC. [Anais...]. \{Sl. : s.n.], 2000.

SANTOS, P. F.; ELKINS, N. Z.; STEINBERGER, Y.; WHITFORD, W. G. A comparison of surface and buried Larrea trdentada leaf litter decomposition in North American hot deserts. Ecology, Tempe, v.65, n. 1. P. 278-284, 1984.

SANTOS, V. D. dos. Ciclagem de nutrientes minerais em mata tropical subcaducifólia dos planaltos do Paraná (parque estadual Vila Rica do Espírito Santo - Fênix/PR). 387 f. Tese (Doutorado em Ciências Biológicas) - Departamento de Ciências Biológicas, Universidade Federal de São Carlos, São Carlos, 1989.

SCHLITTLER, F. H.; DE MARINIS, G.; CESAR, O. Produção de serapilheira na floresta do morro do Diabo, Pontal do Paranapanema - SP. Naturalia, São Paulo, n.18, p.135-147, 1993.

SOUZA, L. C. M. de, SCHLITTLER, H. M. Ciclagem de nutrientes em floresta estacional semidecidual na serra do Japi (município de Jundiaí, SP). In: CONGRESSO DE ECOLOGIA DO BRASIL, 2003, Fortaleza. [Anais...]. [S.1. : s.n.], 2003. p.459-462.

SOUZA, J. S.; ESPÍRITO-SANTO, F. D. B.; FONTES, M. A. L.; OLIVEIRA-FILHO, A. T. de; BOTEZELLI, L. Análise das variações florísticas e estruturais da comunidade arbórea de um fragmento de floresta semidecídua às margens do rio Capivari, Lavras-MG. Viçosa. Revista Árvore, Viçosa, M.G., v. 27, n. 2, p. 185-206, 2003.

STEEL, R. G. D.; TORRIE, J. H. Principles and procedures of statistics. With special reference to the biological sciences. New York : McGraw-Hill,. 1960. 481p.

TEIXEIRA, L. B.; OLIVEIRA, R. F. de; MARTINS, P. F. da S. Ciclagem de nutrientes através da liteira em floresta, capoeira e consórcio com plantas perenes. Revista de Ciências Agrárias, Belém, n. 36, p.19-27, 2001.

TOLEDO, L. O., PEREIRA, M. G., MENEZES, C. E. G. Produção de serapilheira e transferência de nutrientes em florestas secundárias localizadas na região de Pinheiral, RJ. Ciência Florestal, Santa Maria, v. 12, n. 2, p.9-16, 2002.

TREVISAN, G. V. Biomassa e produção de serapilheira no parque Estadual "Mata dos Godoy", Londrina, PR. Londrina, 24 f. Monografia (Graduação em Ciências Biológicas) - Centro de Ciências Biológicas, Universidade Estadual de Londrina, Londrina, 1998.

VELOSO, H. P.; FILHO. A. L. R. R.; LIMA, J. C. A. Classificação da vegetação brasileira, adaptada a um sistema universal. Rio de Janeiro: IBGE, Departamento de recursos Naturais e estudos Ambientais, 1991. 